\title{
The Contribution of the Chemical Industry and the 'Chemiker FH' to the Swiss Economy"
}

\author{
Christof Jud*
}

\begin{abstract}
The Swiss chemical and pharmaceutical industry contributes about $5 \%$ to the gross domestic product of Switzerland. This is significantly above the levels seen in other European economies or in the USA. This industry employs about 68000 people in Switzerland and approximately 1350 ' Chemiker FH', graduates of the Universities of Applied Science. About half of all employed 'Chemiker FH' graduates serve the industry in managerial positions while the other half play a vital role as technical or scientific specialists.

The current evolution at universities throughout Europe towards Bachelor and Master degrees is an important process. 'Chemiker FH' graduates must be allowed equal opportunities in this respect while continuing to cultivate their competitive advantage to 'stay different' (gleichwertig aber andersartig). Welleducated and motivated staff will hereby continue to significantly contribute to a strong backbone of the chemical/pharmaceutical industry in Switzerland.
\end{abstract}

Keywords: Chemical engineer FH · Chemiker FH · Employment · Industrial chemistry ·

Swiss chemical industry · University of Applied Science (UAS)

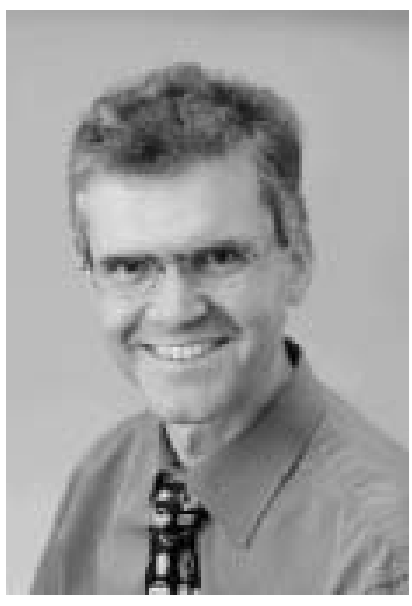

${ }^{\star}$ Correspondence: C. Jud, dipl. Chemiker FH President of SVC (Schweizerischer Verband diplomierter Chemiker FH)

c/o Dow Europe $\mathrm{GmbH}$

Bachtobelstrasse 3

$\mathrm{CH}-8810$ Horgen

Tel.: +411728 2681

Fax: +411728 2992

E-Mail: jud@svc.ch

\#Presented at the $r+d$ in life sciences 2002 congress (Focal Point: Industrial Chemistry) in Basel, on October 18, 2002

\section{The Chemical/Pharmaceutical Industry - A Backbone to the Swiss Economy}

The chemical/pharmaceutical industry in Switzerland has grown dramatically throughout its history. Today, it contributes $5.1 \%$ to the gross domestic product (GDP) of Switzerland (Fig. 1). This is a share that is not even approached in other western economies. The chemical/pharmaceutical industry is the fifth largest sector after financial services, trading, capital equipment, and business services. With a yearly average growth rate of $9.5 \%$ over the last decade it has grown at a significantly higher rate than the GDP. No other sector has experienced a similarly strong trend [1].

Important segments in which the Swiss chemical/pharmaceutical industry has a global leadership position are mainly [2]:

- Pharmaceuticals

- Specialty chemicals

- Diagnostics

- Agro chemicals

- Fragrances and flavors

- Fine chemicals and vitamins

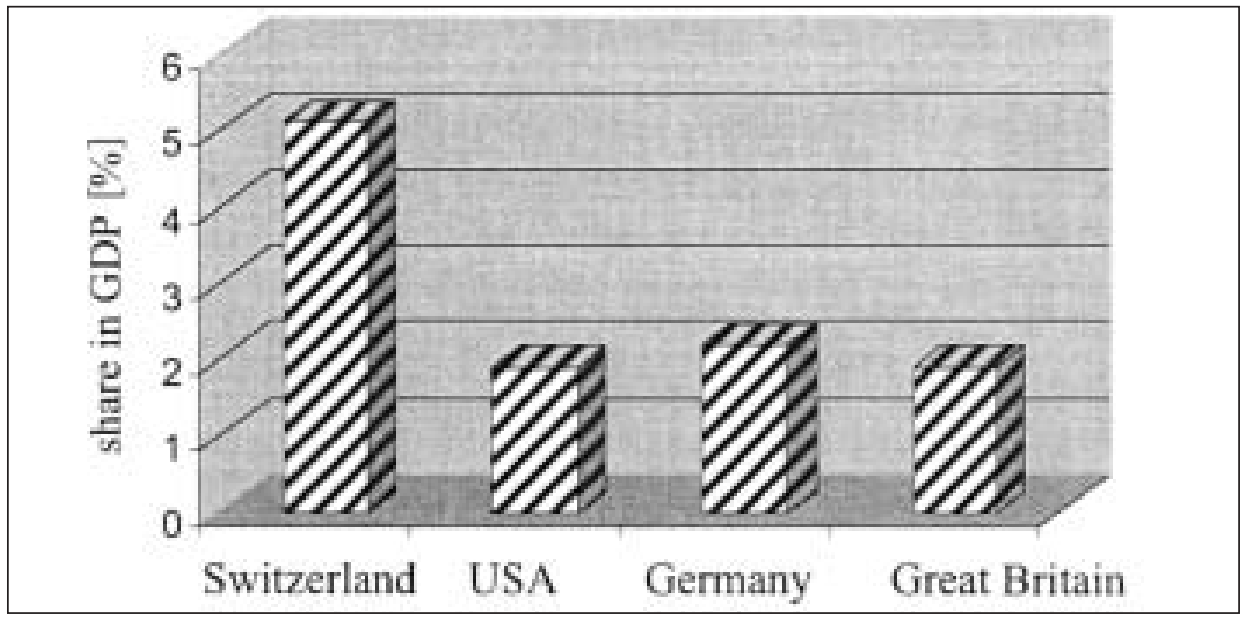

Fig. 1. Contribution of the chemical/pharmaceutical industry to the different economies. 
In 1999 this industry employed 68000 people in Switzerland; around 1350 of these are 'Chemiker FH' or 'Ingénieurs HES en chimie' graduates ('Chemiker FH' employed outside the chemical/pharmaceutical industry are not included in this number). The ten biggest companies employ 32000 people, a number that reflects $14 \%$ of their total global staff. The presence of the small and medium size companies (KMU's) in this industry is equally impressive, as they employ 36000 people (Fig. 2).

\section{'Chemiker FH' and 'Ingénieur HES en chimie' Graduates - A Backbone for the Chemical/Pharmaceutical Industry}

'Chemiker FH' and 'Ingénieur HES en chimie' are vital professions in the chemi$\mathrm{cal} /$ pharmaceutical industry. 'Chemiker FH' graduates work in various fields which range from analytical chemistry to production, development, engineering, marketing, sales, and others. Slightly more than half of all employed 'Chemiker FH' graduates serve the industry in various managerial positions. Half work as technical or scientific specialists and contribute to the success of this industry [3][4]. It can be seen that the industry offers a broad range of fields in which 'Chemiker FH' graduates can be effective:

- Analytical chemistry is a strong

discipline, but also

- development,

- production,

- application technology, and

- engineering

are typical fields of activity for graduates of the Universities of Applied Science (Fig. 3). The strong interest in the listed fields is not surprising. Since the Universities of Applied Science pursue applied research and development they prepare their students for a leading role in the above practically orientated areas. One can also conclude from these numbers that the competitive edge of 'Chemiker FH' graduates to "stay different" (Andersartigkeit) is well established in the industry.

The global presence of the industry needs specialists in chemical engineering and in chemistry and managers who can easily communicate with their colleagues and customers around the globe. 'Chemiker FH' graduates deliver results in true partnership with their colleagues from other European or overseas markets.

- Good language skills,

- effective communication, and

- internationally accepted and comparable education and degrees

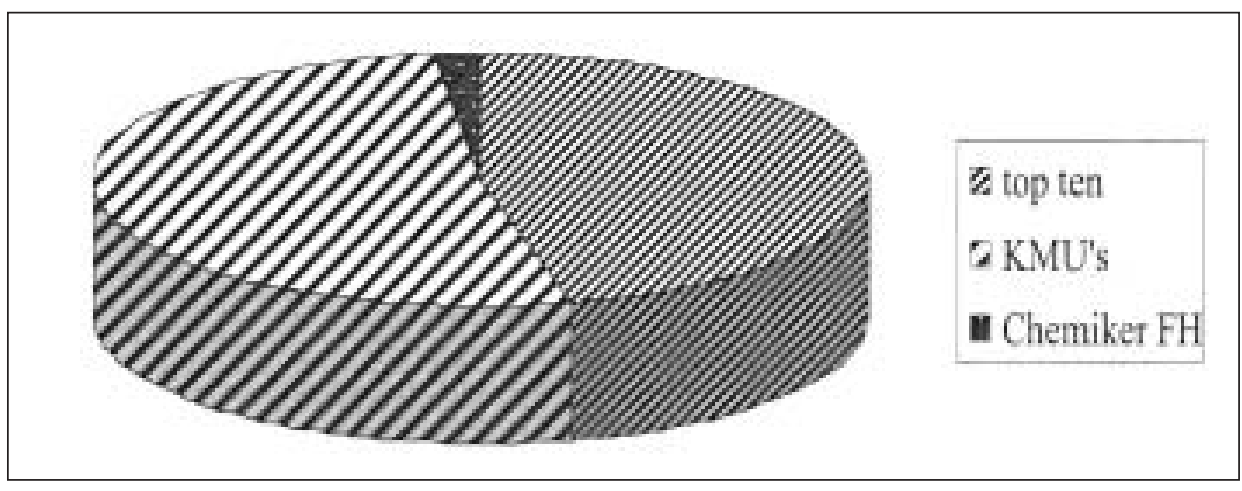

Fig. 2. Employees in the chemical/pharmaceutical industry.

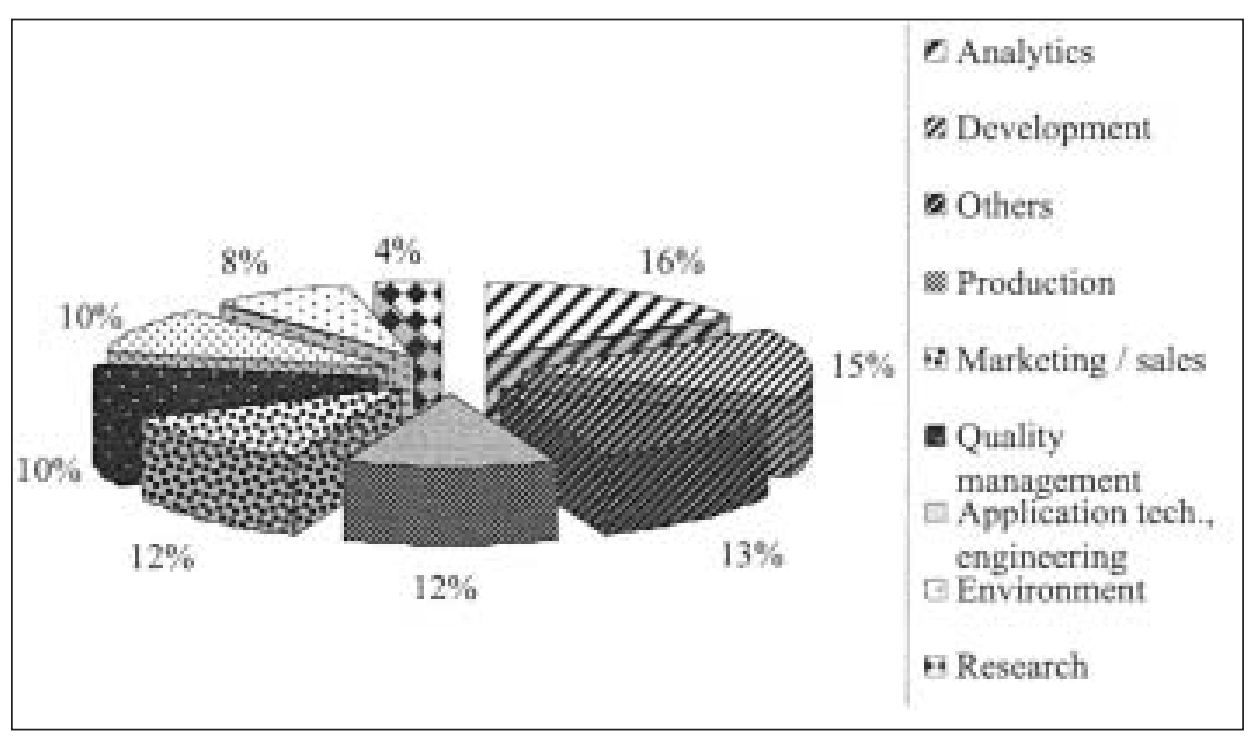

Fig. 3. Working domains of 'Chemiker FH' graduates across the economy.

are only three of the necessary requirements to deliver results in a continuously changing working environment.

\section{A Model Calculation of the Employ- ment Situation for 'Chemiker FH' Graduates in the Chemical Industry}

The following model calculation is based on the best available data from industry responses [5], from the Federal $\mathrm{Bu}$ reau for Statistics [6] and from the member survey conducted by SVC [3]. The data from the chemical/pharmaceutical industry cover only member companies of SGCI [5]. The model gives the best possible quantification of the demand of the industry and of the number of graduates from the Universities of Applied Science. The numbers from surveys were extrapolated to $100 \%$ by assuming the same trends as described by the received responses. Statistical data [6] cover in some cases all faculties at the Univer- sities of Applied Science; in this case the same data are applied to the profession of 'Chemiker FH' in the present model calculation. The number of 'Chemiker FH' graduates are calculated based on data from the annual business reports from those Universities of Applied Science where 'Chemiker FH', 'Ingénieur HES en chimie' or 'Ingénieur HES en génie chimique' courses of study can be taken.

The chemical/pharmaceutical industry quantifies its current annual demand of 'Chemiker FH' graduates to be at $6.2 \%$ of their currently employed staff [5]. The demand from the small and medium size companies is even more pronounced. There are approximately 1350 'Chemiker FH' graduates employed by the Swiss chemical/pharmaceutical industry. This does not include 'Chemiker FH' graduates who are employed in other industries or sectors. This results in an annual demand for new 'Chemiker FH' graduates of 84 and with the tendency increasing (Fig. 4) [5]. 


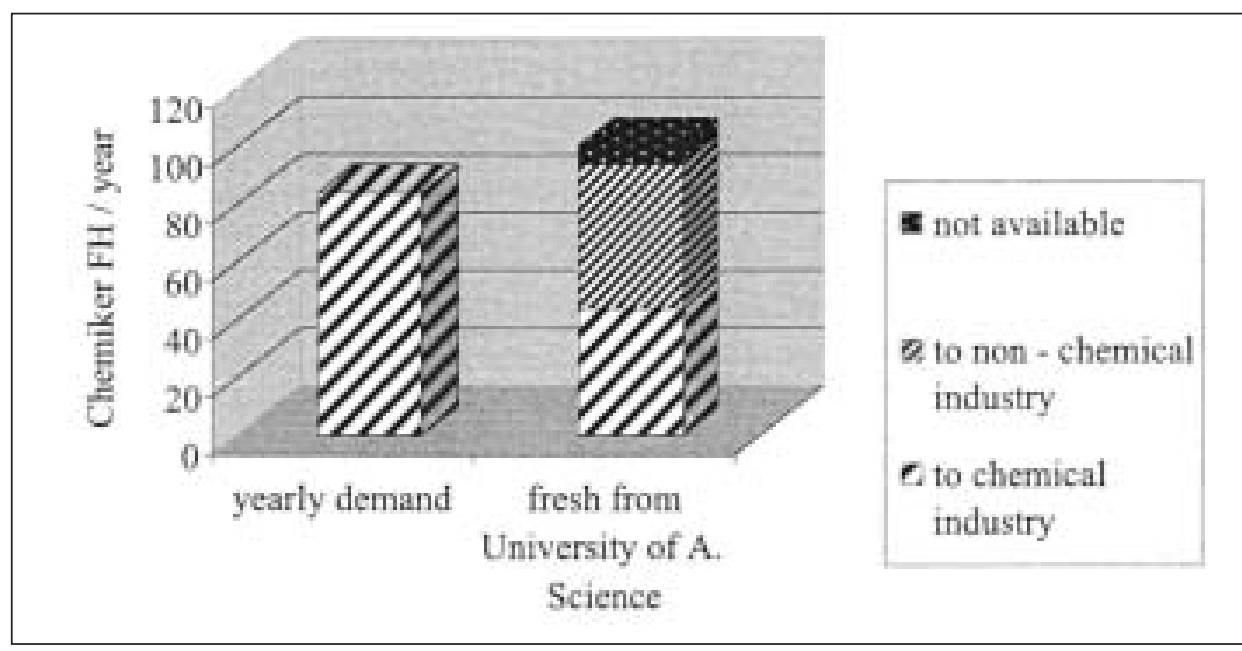

Between 1995 and 2000 an average of 100 'Chemiker FH' per year have graduated from the Universities of Applied Science. The trend has been rather flat if not slightly decreasing. Statistical data show that by 2001 another $6 \%$ of our colleagues became unavailable to the employment market. The numbers from earlier years were even higher. The reasons can be that they are either in the process of changing jobs or have phased out of the employment market due to, for example, family reasons [6]. This means that 94 'Chemiker FH' graduates would potentially remain available to the industry. $53 \%$ of the 'Chemiker FH' graduates joined other industries such as the food, metal, electronic or paper industry or are employed by the public or the service sector [3]. This would decrease the number of 'Chemiker FH' graduates available to the chemical/pharmaceutical industry to 44 per year. The above data allow us to approximate that, considering a fluctuation of approximately $+/-10 \%, 40$ to 50 'Chemiker FH' graduates may enter the chemical/pharmaceutical industry every year (Fig. 4).

The data indicate a significant discrepancy between demand and supply (Fig. 4). A strong effort is needed to make studies in chemistry or chemical engineering at Universities of Applied Science more attractive. The same applies for the preceding apprenticeship. What measures are needed?

Studying chemistry or chemical engineering at a University of Applied Science must result in equal opportunities, be it in the industry, at governmental authorities and other Swiss and foreign universities. Chemistry at the University of Applied Science must still cultivate its character of 'staying different' to contribute to the competitive edge of 'Chemiker FH' graduates who had gained their first practical experiences in a chemical laboratory or on a production site during their apprenticeship [4][7], (gleichwertig aber andersartig).
The ECTS (European Credit Transfer System) must be applicable to the studies at the University of Applied Science in Switzerland. This will allow the students to internationally network and to study and train abroad to prepare for their future careers [8].

The studies must be aligned with the internationally recognizable degrees of a Bachelor and a Master as defined in the declaration of Bologna in 1999. Adjustments on the legislation side are necessary (FHSG, Fachochschulgesetz and FHSV, Fachhochschulverordnung) [9]. Studying chemistry or chemical engineering at a University of Applied Science can never be allowed to lead to a dead end. Should it in the long term not be possible to motivate young people to pursue an apprenticeship and afterwards to study at the Universities of Applied Science, the chemical/pharmaceutical industry will soon suffer from the lack of versatile, creative and effective specialists and managers.

\section{Conclusions}

Some basic requirements must be fulfilled to enable the Universities of Applied Science in Switzerland to satisfy the demand of the chemical/pharmaceutical industry for talented and versatile 'Chemiker FH' graduates also in the future:

- Studying chemistry or chemical engineering at a University of Applied Science must result in equal chances while cultivating 'the difference' as the competitive edge (gleichwertig aber andersartig).

- The ECTS (European Credit Transfer System) must be applicable to the studies at the University of Applied Science.

- The apprenticeship shall be honored appropriately. The apprenticeship gives the necessary practical experience and schooling, both prerequisites when en-
Fig. 4. Employment model calculation for 'Chemiker FH' graduates.

tering the University of Applied Science.

- It must be possible for a potential 'Chemiker FH' student to pursue a Bachelor's and a Master's degree at a University of Applied Science.

- The necessary legislation needs to be implemented without any further delay. The financial investments need to be approved at federal and at cantonal level.

Received: December 5, 2002

[1] 'Garant und Motor für Produktivität und Wohlstand in der Schweiz. Die Bedeutung der chemisch/pharmazeutischen Industrie für die Schweizer Volkswirtschaft', Studie der BAK Basler Konjunkturforschungs AG, 2002.

[2] 'The Swiss Chemical/Pharmaceutical Industry', Schweizerische Gesellschaft für Chemische Industrie, SGCI, 2000.

[3] B. Keller, SVC, 'Salär - Umfrage 2001 SVC', 2001.

[4] Berufsbild Chemiker FH, Chemikerin FH, SVC, 2002.

[5] 'Wisschschaftlich-technischer Nachwuchs', SGCI Umfrage zu Bestand, Trend und Ersatzbedarf naturwissenschaftlich ausgebildeten Personals in schweizerischen Werken, 2001, SGCI (Schweizerische Gesellschaft für Chemische Industrie), 2002.

[6] 'Aktuelle Befunde zur Beschäftigungssituation der Neuabsolventinnen und Neuabsolventen', 'Von der Hochschule ins Berufsleben', Bundesamt für Statistik, 2002.

[7] H. Mey, EFHK, 'Fachhochschulszene Schweiz: Das Fachhochschulgesetz, seine Einführung und seine Auswirkungen auf das tertiäre Bildungssystem', À JOUR 2000 (1/00), 15-19.

[8] 'Ein Streifzug durch die Berichte der Studierenden', EU-Programm ERASMUS, Bundesamt für Bildung und Wissenschaft, 2000, p. 6-9.

[9] T. Jaag, 'Memorandum betreffend Bologna - Deklaration/Fachhochschulen', 2002. 